\title{
Circulating erythroblast abnormality associated with systemic pathologies may indicate bone marrow damage
}

\author{
Stefan Schreier ${ }^{1-3}$, Prapaphan Budchart ${ }^{3}$, Suparerk Borwornpinyo ${ }^{3,4}$, Wichit Arpornwirat ${ }^{5}$, Wannapong Triampo $0^{2,6}$ \\ ${ }^{1}$ School of Bioinnovation and Bio-based Product Intelligence, Faculty of Science, Mahidol University, Rama VI Rd, Bangkok - Thailand \\ ${ }^{2}$ Thailand Center of Excellence in Physics, Ministry of Higher Education, Science, Research and Innovation, Bangkok - Thailand \\ ${ }^{3}$ Premise Biosystems Co., Ltd. Bangkok - Thailand \\ ${ }^{4}$ Excellent Center for Drug Discovery, Faculty of Science, Mahidol University, Rama VI, Rd, Bangkok - Thailand \\ ${ }^{5}$ Department of Oncology, Bangkok Hospital, Bangkok - Thailand \\ ${ }^{6}$ Department of Physics, Faculty of Science, Mahidol University, Bangkok - Thailand
}

\begin{abstract}
Background: The circulating rare cell population is diverse and rich in diagnostic information. Its characterization and clinical exploitation by cell-based liquid biopsy is an ongoing research task. Bone marrow is one of the major contributors to the peripheral blood rare cell population and, consequently, determines individual rare cell profiles thus depending on bone marrow health status. Bone marrow damage has been associated with aggressive or late-stage systemic diseases and egress of various bone marrow cells into the blood circulation. The association of quantity and heterogeneity of circulating erythroblast with bone marrow damage is of particular interest. Methods: Circulating CD71 ${ }^{\text {high }} / C D 45-/ H o e c h s t^{\text {tigh }}$ blast cells from healthy, noncancer- and cancer-afflicted donors were enriched by $C D 45$ depletion and analyzed by immunofluorescence microscopy.

Results: A new finding of aberrant and mitotic circulating erythroid-like cells that appear similar across blood donors afflicted with various systemic pathologies is reported. Further presented is a classification of said erythroblast-like cells in nine subcategories according to morphological differences between phenotypically similar cells. Conclusion: Aberrant and mitotic bone marrow-derived rare circulating erythroid-like cells can be detected in the blood of afflicted individuals but not in healthy donors, suggesting the cause of bone marrow damage.
\end{abstract}

Keywords: Bone cancer, Bone marrow damage, Circulating rare cells, Erythroblast, Liquid biopsy

\section{Introduction}

Advancement in cell-based liquid biopsy (cbLB) comprises aspects of technology and biology $(1,2)$. The latter often focused on the clinical translation of biomarkers mostly comprising known phenotypically specified cell types, such as epithelial, endothelial, or mesenchymal cells (3-5). A new chapter may have been opened with the awareness of the so-called circulating rare cell population (CRP) that holds the potential of cell discovery as well as of comprehensive cell analysis similar to a cytological investigation (6). CRP includes all kinds of non-hematopoietic but also rare hematopoietic

Received: December 7, 2020

Accepted: July 14, 2021

Published online: August 31, 2021

Corresponding author:

Stefan Schreier

School of Bioinnovation and Bio-based Product Intelligence

Faculty of Science

Mahidol University

Rama VI Rd, Bangkok 10400 - Thailand

stefan.scr@mahidol.edu mainly bone marrow-derived cells and suggests a greater influence of bone marrow health status on individual CRP profiles and, most likely, vice versa. Conversely, high diagnostic potential of the CRP, in particular for the assessment of bone marrow damage (BMD), can be deduced yet still, which entails a steep gain in knowledge about character and functionality of individual rare cells (7). One of the most promising markers to be associated with BMD is the circulating erythroblast (CEB). This cell type is a known and common part of the CRP, yet has been rarely investigated for clinical applications in cbLB (6). We have earlier reported on the occurrence of immature CEB-like cells in healthy donors and suggested the association of respective findings above baseline with underlying pathologies affecting the bone marrow (8). Our data presented support of the hypothesis that increased levels of CEB predict BMD caused by chronic and systemic diseases. We herein report a new finding of erythroid cell abnormality with respect to poly-nucleation, cell pairing, and aggregation in association with systemic pathologies. The implications of the findings of, in particular, morphologically aberrant CEB would represent cytological evidence of BMD and be far-reaching for care in systemic diseases, for example, for the evidence-based prediction of distant invasion in cancer. As a first step into this research, we intend to describe 
and classify the newly found CEB abnormalities as part of CRP associated with systemic disorders and provide first-hand evidence of the association with BMD.

\section{Theory of liquid biopsy-based BMD detection}

In cancer, BMD is an expected consequence of invasion by aggressive tumor cells referred to as disseminated tumor cells (DTC) and may entail a systemic response by way of egress of bone marrow cellular components that forms abnormal CRP profiles (6). Consequently, BMD detection in the setting of a cancer diagnosis is predictive of aggressive distant invasive disease. Relevant circulating cell types being indicative of and highly sensitive to slightest BMD are erythroid precursors that vary in quantity and maturation state upon bone marrow imbalances (8). CEB concentrations may vary in the range of $<1$ to $2 \times 10^{5}$ cells $/ \mathrm{mL}$ depending on age, lifestyle in the lower concentration regimen, and disease type and severity in the higher concentration regimen, respectively. The pathological mechanism behind erythroblast egress as well as abnormalities is not well understood in particular for nonerythroid pathologies. We suggest at least two pathologies at work. One is the dysregulation of erythropoiesis, another is a dysfunctional blood barrier. We theorize that a change in the micro-environment of the so-called erythroid islands (9) at the vascular niche is caused by stress, for example, by invasion and nesting of aggressive DTC. Stress may be caused by inducing hypoxic conditions or by interaction with the erythroblast committed central macrophage or the erythroblasts themselves $(10,11)$. Hypoxia develops in growing tumors, suggesting that active/aggressive DTC may induce hypoxia in the bone marrow micro-environment as well and may outstrip their ability to take up oxygen and nutrients from their environment by diffusion. Tumor-induced hypoxia is associated with poor prognosis (12). Furthermore, DTC are theorized to be in competition with erythroblasts for physical interaction with the central macrophage, and then changing the activation state of the central macrophage in the erythroid island most likely causing inflammatory cell recruitment, dysregulation of erythroblast proliferation and maturation, and destabilization of the vascular integrity. Furthermore, erythroblast cell cycle defects may be caused by altered mitochondrial function (13).

\section{Methods}

\section{Patient cases}

Nonspecific systemic pathologies were chosen to investigate the presence of CEB abnormality comprising a late- and early-stage breast cancer sample taking liquid biopsy before palliative treatment and after surgery and during chemoadjuvant therapy treatment, respectively. The collection further comprised an extensive stage small cell lung cancer (SCLC) patient taking a liquid biopsy during 3rd line chemotherapy therapy and a stage 4 non-small cell lung adenocarcinoma before palliative treatment. Another liquid biopsy was taken from a stage 3 head and neck cancer patient during chemotherapy. Furthermore, subjectively healthy persons with known underlying pathologies included three individuals afflicted with diabetes type II, osteoporosis, and thrombocytosis, respectively. Informed consent was sought from the patient at the time of the blood draw in accordance with institutional review board (IRB) protocol.

\section{Detection platform}

The cbLB procedure has been described in our previous publication with modifications (8). In brief, $5 \mathrm{~mL}$ blood taken from 17 healthy donors and 4 cancer patients was subjected to pre-enrichment by red blood cell lysis yielding highly purified nucleated cells in the range of $1.8 \mathrm{e} 7$ to $5.5 \mathrm{e} 7$ cells. The cell suspension was further enriched by CD45 depletion assay employing an automated magnetic cell enrichment platform (Walderbach I, SanoLibio GmbH, Muenchen). The resulting cell suspension comprised carry-over leukocytes counting 3000 cells on average and all sorts of CD45-negative rare cells, among them CEB. In order to visualize their presence, the enriched cell suspension was subjected to cell membrane staining by conjugate antibodies reactive against CD71 and CD45 in both cases and nucleus staining by Hoechst Blue DNA stain. For analysis, the sample suspensions were loaded into a 386-well plate suitable for high-resolution image recording at $40 \times$ magnification using the Operetta system (PerkinElmar) and recording a bright field channel, channels for UV, green, and yellow fluorescence emission. Columbus analysis software served as screening and image analysis tool. Cells were identified as CEB in case of high expression of CD71 along the membrane, high nucleus density as well as complete absence of CD45 marker signal.

\section{Results}

We have identified known but also thus far unreported CEB morphologies exclusively in diseased individuals that follow in principle typical descriptions of erythroblast morphology and erythroid-specific CD71 ${ }^{\text {High }} / \mathrm{CD} 45-/$ Hoechst $^{\text {High }}$ phenotype. Detected cell morphologies could be recognized across diseases and therefore grouped into four main morphological distinct types which could be further divided into a total of nine subtypes (Fig. 1). Type 1 CEB represents normal erythroblasts and were found commonly in healthy donor blood at low concentrations, which can be further grouped into small (type 1a) and large (type 1b) erythroblasts owing to the size differences to the erythroblast maturation process (8). Type $1 \mathrm{a}$ is the most abundant cell type in all samples and represents the matured circulating counterpart of otherwise bone marrow dwelling orthochromatic erythroblasts with diameters in the range of $6.5 \mu \mathrm{m}$ to about $12.4 \mu \mathrm{m}$. Type 1a cells corresponded to the commonly described appearance with dense nuclei and a high nucleus to cytoplasm ratio ( $\mathrm{N} / \mathrm{C}$ ratio). Class $1 \mathrm{~b}$ denotes less frequent large CEB with diameters exceeding 12.4 $\mu \mathrm{m}$ as previously described (8). Apart from the size, immaturity is represented by a low-density chromatin nuclei in the diameter of about $6 \mu \mathrm{m}$ to $10 \mu \mathrm{m}$ and exhibiting a low N/C. Type 1 CEB may reflect abnormal erythropoiesis by cell elevation above normal concentrations only (Tab. I). Type 1 CEB could be further divided into subtypes $1 \mathrm{c}$ and $1 \mathrm{~d}$ comprising 


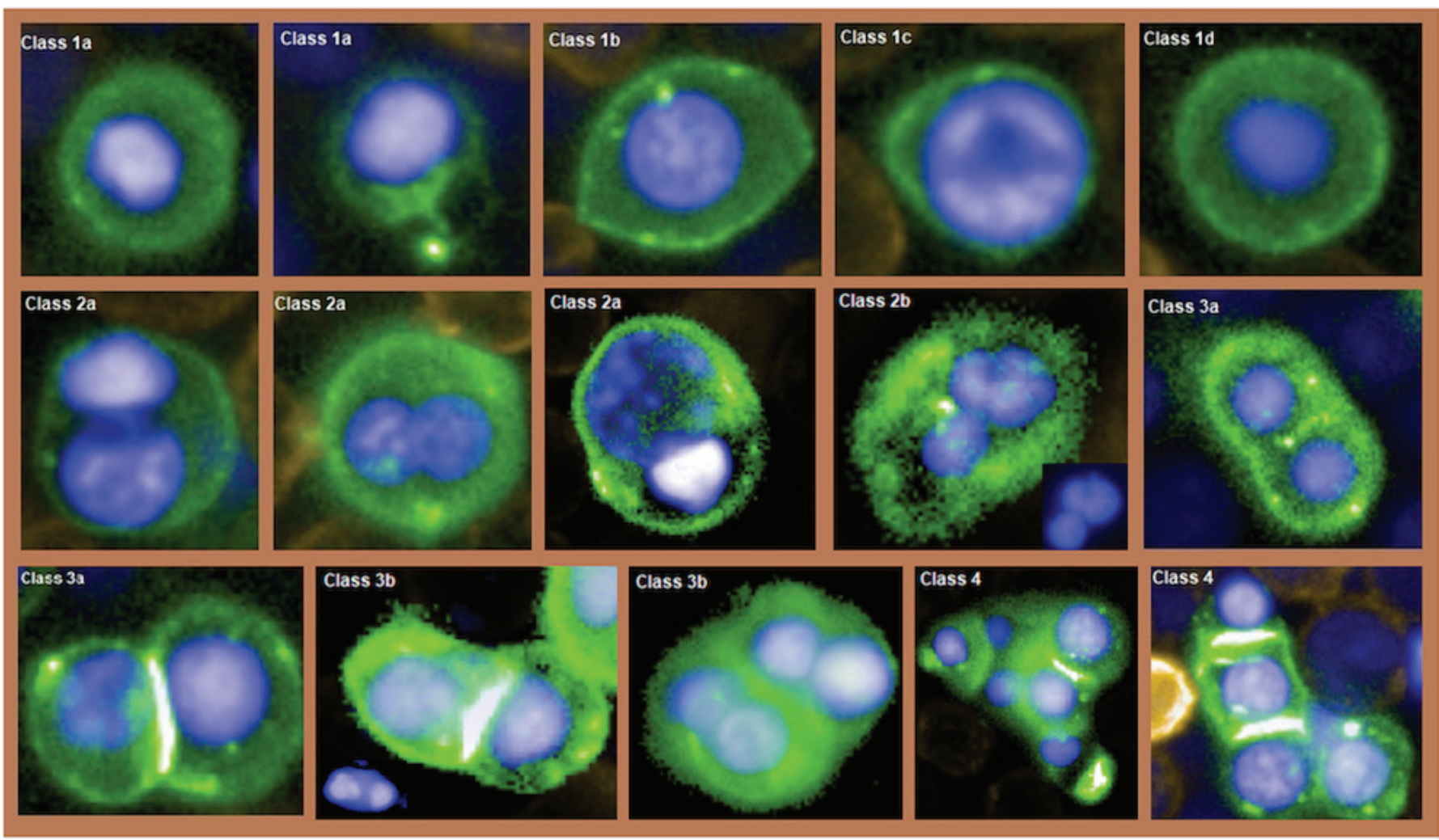

Fig. 1 - Gallery of CD71 high $/ C D 45-/$ Hoechst ${ }^{\text {tigh }}$ circulating erythroblast (CEB) types. From left to right and upper to lower. The first two images represent normal erythroblasts measuring $10.5 \mu \mathrm{m}$ and $7 \mu \mathrm{m}$ in diameter, respectively. Next is shown a class $1 \mathrm{~b}$ large CEB with low chromatin density measuring $14 \mu \mathrm{m}$ in major diameter. Next is shown a megaloblast presenting irregular chromatin texture and is followed by a macronormoblast. The following two images represent symmetric type $2 a$ binucleated CEB. The next image represents an asymmetric aberrant type $2 \mathrm{a}$ binucleated CEB. Next is shown a type $2 \mathrm{~b}$ CEB and is characteristic of a binucleated and multilobulated nucleus. The next two images represent symmetric mitotic CEB of class $3 a$. Next is shown a type $3 \mathrm{~b}$ mitotic CEB with apparent chromatin bridging and a type $3 \mathrm{~b}$ CEB showing symmetric and asymmetric mitosis. The last two images represent type 4 CEB aggregates revealing nucleus variations in size and maturation.

Table I - Patient findings

\begin{tabular}{|c|c|c|c|c|c|c|c|c|c|c|}
\hline Patient type & Patient description & $\begin{array}{c}\text { Type } \\
\text { 1a }\end{array}$ & $\begin{array}{l}\text { Type } \\
\mathbf{1 b}\end{array}$ & $\begin{array}{l}\text { Type } \\
\text { 1c }\end{array}$ & $\begin{array}{l}\text { Type } \\
\text { 1d }\end{array}$ & $\begin{array}{c}\text { Type } \\
2 a\end{array}$ & $\begin{array}{c}\text { Type } \\
\text { 2b }\end{array}$ & $\begin{array}{c}\text { Type } \\
\mathbf{3 a}\end{array}$ & $\begin{array}{c}\text { Type } \\
\text { 3b }\end{array}$ & $\begin{array}{c}\text { Type } \\
4\end{array}$ \\
\hline $\begin{array}{l}\text { 1. Breast cancer, late } \\
\text { stage }\end{array}$ & $\begin{array}{l}\text { Treatment-naive recurrent } \\
\text { breast cancer and bone, liver } \\
\text { metastasis }\end{array}$ & 3219 & 13 & 46 & 10 & 257 & 1 & 515 & 2 & 1260 \\
\hline \multirow[t]{2}{*}{$\begin{array}{l}\text { 2. Breast cancer, early } \\
\text { stage }\end{array}$} & $\begin{array}{l}\text { Postsurgery baseline, stage } 2 \text {, } \\
\text { lymph node negative }\end{array}$ & 2 & None & None & None & 2 & None & None & None & None \\
\hline & Mid-term ACT & 62 & 3 & 6 & None & 1 & None & 2 & None & None \\
\hline $\begin{array}{l}\text { 4. Lung adenocarcinoma, } \\
\text { late stage }\end{array}$ & Treatment naive, stage 4 & 81 & 9 & None & None & 4 & None & 4 & None & None \\
\hline $\begin{array}{l}\text { 5. Head and neck, } \\
\text { advanced stage }\end{array}$ & Under treatment & 5 & None & None & None & None & None & 1 & None & None \\
\hline
\end{tabular}

$\mathrm{ACT}$ = adjuvant chemotherapy.

Numbers denote cell concentrations per $5 \mathrm{~mL}$ whole blood. 
so-called megaloblasts and macro-normoblasts, respectively. The finding of such abnormal morphologies in the circulation represents evidence of dyserythropoiesis and predicts a pathological state of the bone marrow $(14,15)$. Megaloblasts show nucleocytoplasmic asynchrony and moderate to high and intracellular chromatin heterogeneity and high N/C ratio. Macro-normoblasts show no nucleocytoplasmic asynchrony, total condensation nuclei in a diameter of about $4 \mu \mathrm{m}$ to $6 \mu \mathrm{m}$, and a very low N/C ratio. Type 2 CEB denotes an apparently relatively frequent morphological abnormality in both nonmalignant and malignant diseases and is characterized by symmetric multi-nucleation in a single cell most likely ascribed to asynchronous mitosis. Type 2 CEB may also vary in size and shape and includes aberrant cell types containing nuclei that differ in size and maturation (Fig. 1). We further divided type 2 CEB into binucleated (type 2a) and multinucleated or multinuclear lobulation single cells (type $2 \mathrm{~b}$ ) following World Health Organization (WHO) descriptions of bone marrow erythroblast abnormality (16). Different underlying pathologies and/or stages may be causative of the number of nuclei in a single cell, for example, in the classification of congenital dyserythropoietic anemia in which types I-IV directly correlate with the number of erythroblast nuclei (17). Myelodysplastic syndromes may produce three or more nucleated, yet mostly binucleated erythroblasts (15). Type 3 CEB denotes cells in synchronous mitosis at various stages from metaphase till cytokinesis and seems to occur across disease types as frequent as type $2 a$ CEB. This type could be further divided into symmetric (type 3a) and aberrant (type 3b) cell morphologies. The latter includes CEB pairs showing internuclear bridging or containing nuclei that differ in size, number, and maturation (Fig. 1). Type 4 comprises cells appearing in groups of at least three round or oval, normal or binucleated cells and represents the morphological aspect of a cell cluster. These cells may be seen to be in division or constitute a breakaway of aggregated erythroblasts from an erythroid island within the bone marrow. Type 4 CEB is only found in late-stage malignancies.

Apart from types $1 a$ and $b$, all other herein reported types were not found in the healthy cohort (8) (Tab. I). Therefore CEB types $1 c, d, 2,3$, and 4 are herein referred to as abnormal and would denote bone marrow defects to some extent. According to Table I, the CEB profile with regard to heterogeneity and cell number may be positively correlated with disease severity, suggesting a relatively high sensitivity toward slightest physiological imbalances of the bone marrow.

\section{Discussion}

CRP is expected to convey a wealth of diagnostic information ascribed to lesion-associated cell egress into the blood stream or to tissue repair or maintenance. It is good to say that the rarest population of cells is most decisive for, and thus informative of, our health. Rare cells associated with tissue repair may comprise bone marrow-derived progenitor and stem cells. Those rare cells associated with lesions may comprise respective tissue-derived mature somatic cells, such as epithelial or endothelial cells. The diagnostic exploitation of a single, a few, or all detectable circulating rare cells in a sample is referred to as cbLB. Our investigation in that field, in particular on the circulating CD71 high phenotype, has revealed a staggering variety of morphologies across different diseases that are seemingly not associated with pathological erythropoiesis and seem to correspond to findings of erythroid abnormality as could be found in the bone marrow (15). Erythrobast abnormality has been rarely reported to circulate, and to the best of our knowledge only in case of diseases with underlying pathological erythropoiesis (18). Apart from systemic diseases, treatment by chemotherapy is known to elevate CEB concentration (11), suggesting that CEB abnormality in patient 3 may be caused or influenced by chemotherapy. The two samples of patient 2 before and during chemoadjuvant therapy, respectively, would also support chemotherapy-induced CEB elevation.

We would like to take the opportunity to suggest possible clinical usefulness of our findings. The assumption is that CEB abnormality would denote sufficient cytological evidence to diagnose bone marrow defects and would allow us to grade BMD based on cell quantity and type. Cell aberration, in particular, and/or the finding of type 4 CEB could provide evidence for the association with more severe BMD as has been found exclusively in metastatic cancer (patients 1 and 3). Our thoughts about CEB abnormality and the association with BMD may be supported by investigations of the bone marrow pathology reporting similar erythroblast abnormality in case of severe bone marrow diseases, such as leukemia or hereditary anemia (18-20).

When applied to cancer, in particular early stage cancer patients may benefit from correct assessment of individualized distant invasion profiles (21) however, conventional functional imaging methods are not capable of detecting potentially hazardous distant micro-metastasis. Also, the detection of circulating tumor cells (CTCS) only predicts metastases based on statistics $(22,23)$. Moreover, bone marrow biopsy may provide pathological evidence of distant disease development at the individual level, yet is not routinely performed given the patient risk by the procedure and low discrimination power between dormant and active invasion. Positive findings of tumor cell dissemination at earliest stages were commonly reported from bone marrow biopsies (24-26). Despite the evidence to support prognostic significance in early-stage breast cancer patients (27-30), bone marrow micro-metastases assessment (BMMA) as prognostic marker for relapse was found invariant to existing treatment decision making and, thus, was not adopted into clinical routine ever since (31). Henceforth, the diagnostic question of BMMA and single-cell invasion must be shifted from the status of distant invasion to distant aggressiveness, that is, BMD. The detection of CEB via cbLB could be a wellsuited and better alternative to BMMA given the improved stratification power between dormant or inactive and active tumor cell invasion. We can expect from our data that dormant metastases would not produce marked CEB profiles and, vice versa, active disease would generate detectable CEB profiles. Finally, our BMD detection platform may tap into the exciting notion of CTC/DTC-guided treatment decision based on tumor evolution (32). 


\section{Conclusion}

The study investigated circulating erythroid nucleated cells in the blood of healthy and afflicted individuals. Bone marrow-derived erythroblasts were identified in each blood donor by positive CD71 staining and typical erythroblast morphology confirming commonness as part of the blood rare cell population. Furthermore, abnormal erythroblast-like cells as known to the pathologist from bone marrow biopsies were found only in diseased individuals in this study. This report is mainly dedicated to the new finding of aberrant and mitotic erythroblast-like cells that are so far unknown to circulate in the blood of diseased individuals foremost in cancer patients. The cell abnormality could be coarsely classified into synchronous and asynchronous mitosis, respectively, and is likewise suspected to be bone marrow-derived, consequently indicating various degrees of BMD. A new cancer biomarker panel could be established in cbLB when used in combination with circulating epithelial cells as a potential detection and grading platform of cancer-associated active distant invasion.

\section{Acknowledgments}

We would like to give special thanks to Dr. Kanakorn Runglodvatana from Vajira Hospital, Bangkok, for providing head and neck cancer patient blood donation.

\section{Ethics Approval and Consent to Participate}

The study subject titled "Advancing cell-based liquid biopsy" was approved by the Mahidol University Central IRB, Mahidol University, with protocol number 2019/197.3007. All healthy donors were appointed, informed, and consented in written form. In case of the three cancer patient cases, study information was provided by the treating doctor and consent was given by the patient verbally, respectively during out patient consultation, due to very limited visitation time.

\section{Abbreviations}

$\mathrm{ACT}$ = adjuvant chemotherapy; $\mathrm{BMD}=$ bone marrow damage; $\mathrm{BMMA}=$ bone marrow micro-metastases assessment; cbLB = cell-based liquid biopsy; $C E B$ = circulating erythroblast or circulating erythroblast-like cell; $\mathrm{CTC}=$ circulating tumor cell; DTC = disseminated tumor cells; $\mathrm{H} \& \mathrm{~N}=$ head and neck cancer; N/C ratio: nucleus to cytoplasm ratio; $\mathrm{RCP}=$ rare cell population; $\mathrm{SCLC}=$ small cell lung cancer.

\section{Disclosures}

Conflict of interest: SS and SB are shareholders of the companies involved in the development and manufacturing of cell separation technology and biomarkers as was employed in this work. Financial support: The study was partly funded by Mahidol University. Authors' contribution: SS conceived and designed the study, carried out imaging analysis, and drafted the manuscript. PrB carried out experimentation and took part in image analysis. PB reviewed the study and took part in drafting the manuscript. WA reviewed the study and took part in drafting the manuscript. WT advised the study, and drafted and reviewed the manuscript. All authors read and approved the final manuscript.

\section{References}

1. Millner LM, Linder MW, Valdes R Jr. Circulating tumor cells: a review of present methods and the need to identify heterogeneous phenotypes. Ann Clin Lab Sci. 2013;43(3):295-304. PubMed

2. Alix-Panabières $C$, Pantel $K$. Clinical applications of circulating tumor cells and circulating tumor DNA as liquid biopsy. Cancer Discov. 2016;6(5):479-491. CrossRef PubMed

3. Allard WJ, Matera J, Miller MC, et al. Tumor cells circulate in the peripheral blood of all major carcinomas but not in healthy subjects or patients with nonmalignant diseases. Clin Cancer Res. 2004;10(20):6897-6904. CrossRef PubMed

4. Bhakdi SC, Suriyaphol P, Thaicharoen $P$, et al. Accuracy of tumour-associated circulating endothelial cells as a screening biomarker for clinically significant prostate cancer. Cancers. 2019;11:1064. CrossRef PubMed

5. Jones ML, Siddiqui J, Pienta KJ, Getzenberg RH. Circulating fibroblast-like cells in men with metastatic prostate cancer. Prostate. 2013;73(2):176-181. CrossRef PubMed

6. Schreier $S$, Wannapong $T$. The blood circulating are cell population. What is it and what is it good for? Cells. 2020;9(4):790. CrossRef PubMed

7. Fadini GP, Avogaro A. It is all in the blood: the multifaceted contribution of circulating progenitor cells in diabetic complications. Exp Diabetes Res. 2012;2012:742976. CrossRef PubMed

8. Schreier S, Borwornpinyo S, Udomsangpetch R, Triampo W. An update of circulating rare cell types in healthy adult peripheral blood: findings of immature erythroid precursors. Ann Transl Med. 2018;6(20):406. CrossRef PubMed

9. Bessis M. L'ilot erythroblastique. Unite functionelle de la moelle osseuse. Rev Hematol (Paris). 1958;13:8-11.

10. Spike BT, Macleod KF. Effects of hypoxia on heterotypic macrophage interactions. Cell Cycle. 2007;6(21):2620-2624. CrossRef PubMed

11. Kobayashi $Y$, Takamatsu R, Sato S, et al. Erythroblast appearance associated with natalizumab. Mult Scler Relat Disord. 2019;29:145-147. CrossRef PubMed

12. Du R, Lu KV, Petritsch C, et al. HIF1a induces the recruitment of bone marrow-derived vascular modulatory cells to regulate tumor angiogenesis and invasion. Cancer Cell. 2008;13:206-220.

13. Sankaran VG, Orkin $\mathrm{SH}$, Walkley $\mathrm{CR}$. Rb intrinsically promotes erythropoiesis by coupling cell cycle exit with mitochondrial biogenesis. Genes Dev. 2008;22:463-475.

14. Downey $\mathrm{H}$. The megaloblast-normoblast problem: a cytologic study. J Lab Clin Med. 1952;39(6):837-864. PubMed

15. Goasguen JE, Bennett JM, Bain BJ, et al; The International Working Group on Morphology of MDS. Dyserythropoiesis in the diagnosis of the myelodysplastic syndromes and other myeloid neoplasms: problem areas. Br J Haematol. 2018;182(4):526533. CrossRef PubMed

16. Brunning RD, Orazi A, Germing U. Myelodysplastic syndromes/ neoplasms, overview. In: World health organization classification of tumours of haematopoietic and lymphoid tissues 2008.

17. Iolascon A, Heimpel H, Wahlin A, Tamary H. Congenital dyserythropoietic anemias: molecular insights and diagnostic approach. Blood. 2013;122(13):2162-2166. CrossRef PubMed

18. Jaffray JA, Mitchell WB, Gnanapragasam MN, et al. Erythroid transcription factor EKLF/KLF1 mutation causing congenital dyserythropoietic anemia type IV in a patient of Taiwanese origin: review of all reported cases and development of a clinical diagnostic paradigm. Blood Cells Mol Dis. 2013;51(2):71-75. CrossRef PubMed

19. Zhao B, Liu H, Mei Y, et al. Disruption of erythroid nuclear opening and histone release in myelodysplastic syndromes. Cancer Med. 2019;8(3):1169-1174. CrossRef PubMed 
20. Bright M, Cobb J, Evans B, Parry TE. Congenital dyserythropoietic anaemia with erythroblastic multinuclearity. J Clin Pathol. 1972;25(7):561-569. CrossRef PubMed

21. Pantel K, Cote RJ, Fodstad O. Detection and clinical importance of micrometastatic disease. J Natl Cancer Inst. 1999;91(13):11131124. CrossRef PubMed

22. Klein CA, Blankenstein TJ, Schmidt-Kittler O, et al. Genetic heterogeneity of single disseminated tumour cells in minimal residual cancer. Lancet. 2002;360(9334):683-689. CrossRef PubMed

23. Tharp D, Nandana S. How prostate cancer cells use strategy instead of brute force to achieve metastasis. Cancers (Basel). 2019;11(12):1928. CrossRef PubMed

24. Diel IJ, Kaufmann M, Goerner R, Costa SD, Kaul S, Bastert G. Detection of tumor cells in bone marrow of patients with primary breast cancer: a prognostic factor for distant metastasis. J Clin Oncol. 1992;10(10):1534-1539. CrossRef PubMed

25. Walter VP, Taran FA, Wallwiener M, Brucker SY, Hartkopf AD . Abstract P1-01-16: Detection of disseminated tumor cells in DCIS patients impacts local recurrence. San Antonio Breast Cancer Symposium; December 5-9, 2017; San Antonio, Texas. Cancer Res. 2018. CrossRef

26. Banys M, Hahn M, Gruber I, et al. Detection and clinical relevance of hematogenous tumor cell dissemination in patients with ductal carcinoma in situ. Breast Cancer Res Treat. 2014;144(3):531-538. CrossRef PubMed
27. Cote RJ, Rosen PP, Lesser ML, Old LJ, Osborne MP. Prediction of early relapse in patients with operable breast cancer by detection of occult bone marrow micrometastases. J Clin Oncol. 1991;9(10):1749-1756. CrossRef PubMed

28. Mignot $F$, Loirat $D$, Dureau $S$, et al. Disseminated tumor cells predict efficacy of regional nodal irradiation in early stage breast cancer. Int J Radiat Oncol Biol Phys. 2019;103(2):389-396.

29. Braun S, Vogl FD, Naume B, et al. A pooled analysis of bone marrow micrometastasis in breast cancer. N Engl J Med. 2005;353(8):793-802. CrossRef PubMed

30. Stefanovic $S$, Diel I, Sinn P, et al. Disseminated tumor cells in the bone marrow of patients with operable primary breast cancer: prognostic impact in immunophenotypic subgroups and clinical implication for bisphosphonate treatment. Ann Surg Oncol. 2016;23(3):757-766. CrossRef PubMed

31. Harris L, Fritsche H, Mennel R, et al; American Society of Clinical Oncology. American Society of Clinical Oncology 2007 update of recommendations for the use of tumor markers in breast cancer. J Clin Oncol. 2007;25(33):5287-5312. CrossRef PubMed

32. Banys-Paluchowski M, Hartkopf A, Meier-Stiegen F, Janni W, Solomayer EF, Fehm T. Circulating and disseminated tumour cells in breast carcinoma: Report from the Consensus Conference on Tumour Cell Dissemination during the 38th Annual Meeting of the German Society of Senology, Berlin, 14 June 2018. Geburtshilfe Frauenheilkd. 2019;79(2):177-183. CrossRef PubMed 